\title{
Khorbas: a Lower Palaeolithic site on Qeshm Island in the Persian Gulf
}

\author{
Sirvan Mohammadi Ghasrian*
}

Despite the potential importance of southern Iran, and the Persian Gulf area in particular, for discussions on the dispersal of early hominins from Africa into Eurasia during the late Pliocene and early Pleistocene (Bar-Yosef \& Belfer-Cohen 2001; Rose 2010), this area has remained almost unexplored until recently. Historically, Palaeolithic survey and excavations in Iran have mainly concentrated in western regions, especially the Zagros Mountains. As a result of recent studies, however, evidence for Palaeolithic sites in the southern regions of Iran, from Fars province to Qeshm Island, has greatly increased (Dashtizade 2009, 2010). Even with this improvement, no sites of Lower Palaeolithic date have yet been reported from the southern coastal areas on one of the proposed early hominin routes into Eurasia. As a result, it has been suggested that the few Lower Palaeolithic sites reported from other parts of Iran, especially in the west (e.g. Biglari \& Shidrang 2006), were not populated from the south.

In order to show that this hypothesis is not correct and that the southern coastal area of Iran has the capability to provide evidence of Lower Palaeolithic groups, extensive survey was conducted on Qeshm Island, which was considered a location likely to produce evidence for early Palaeolithic activity. Reconnaissance was focused on the elevated areas of the island, with its caves and rockshelters. An assemblage of Palaeolithic artefacts was discovered at the Khorbas Cave and rockshelters on the present-day coastline of the island. In addition to Palaeolithic artefacts, the survey also recorded historic and late Islamic pottery at the site. In addition, a number of other sites, all of historic date, were identified on the island.

The Khorbas site is located 10km south-west of Qeshm City on the Persian Gulf coast (Figure 1). The site had been previously surveyed by both Iranian (Khosrowzadeh 2005) and foreign scholars (Potts \& Petrie 2004), but the oldest archaeological evidence reported to date reached back only to the Parthian era (Potts \& Petrie 2004; Khosrowzadeh 2005). The majority of finds belong to recent Islamic times, when the area seems to have served as a port. The site was resurveyed by a team directed by the present author, and although it had been badly damaged by recent activities, including road construction, an assemblage of Palaeolithic artefacts was identified. This included handaxes, a chopper, a hammerstone and a core; a number of flakes were also recovered and even though these cannot be attributed to the Palaeolithic on stylistic grounds, they were, however, recovered from the same concentration as the tools (Figures 2-6). Due to the absence of suitable raw material

Iranology Foundation, Kurdistan Branch, Ghatarchian, Boulevard of Kurdistan, Amin-al-eslam House, Sannandaj, P.O. Box 6613754774, Kurdistan, Iran (Email: mohammadisirvan@gmail.com) 

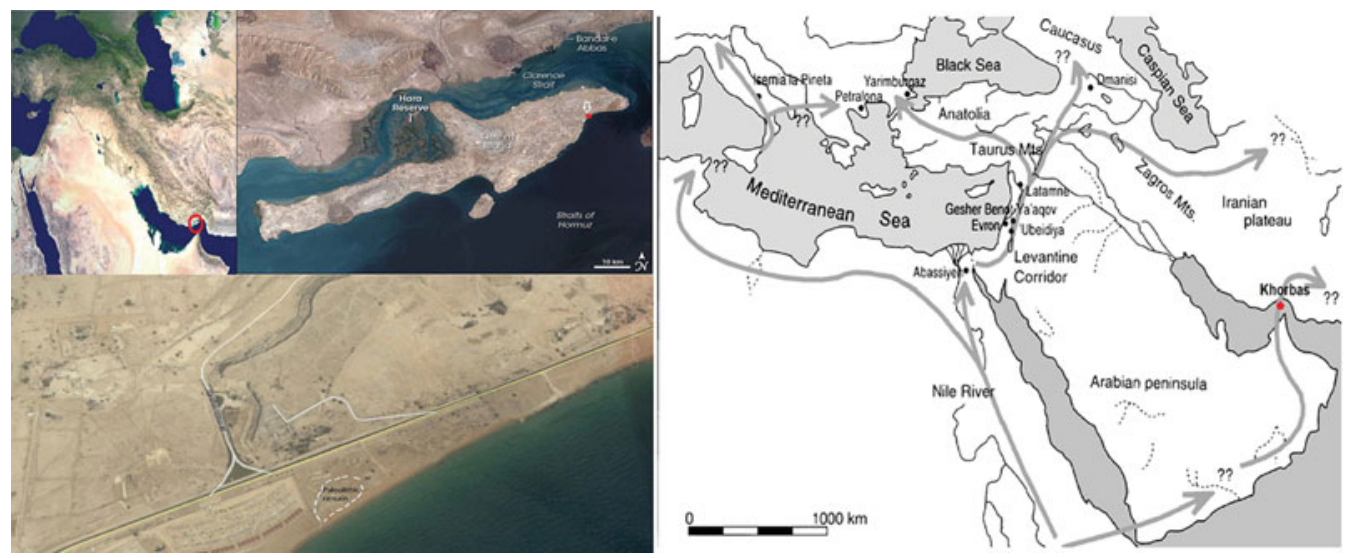

Figure 1. Location of the Khorbas site on Qeshm Island (left) and location of one of the proposed routes of early hominin dispersal (right; after Bar-Yosef \& Belfer-Cohen 2001).

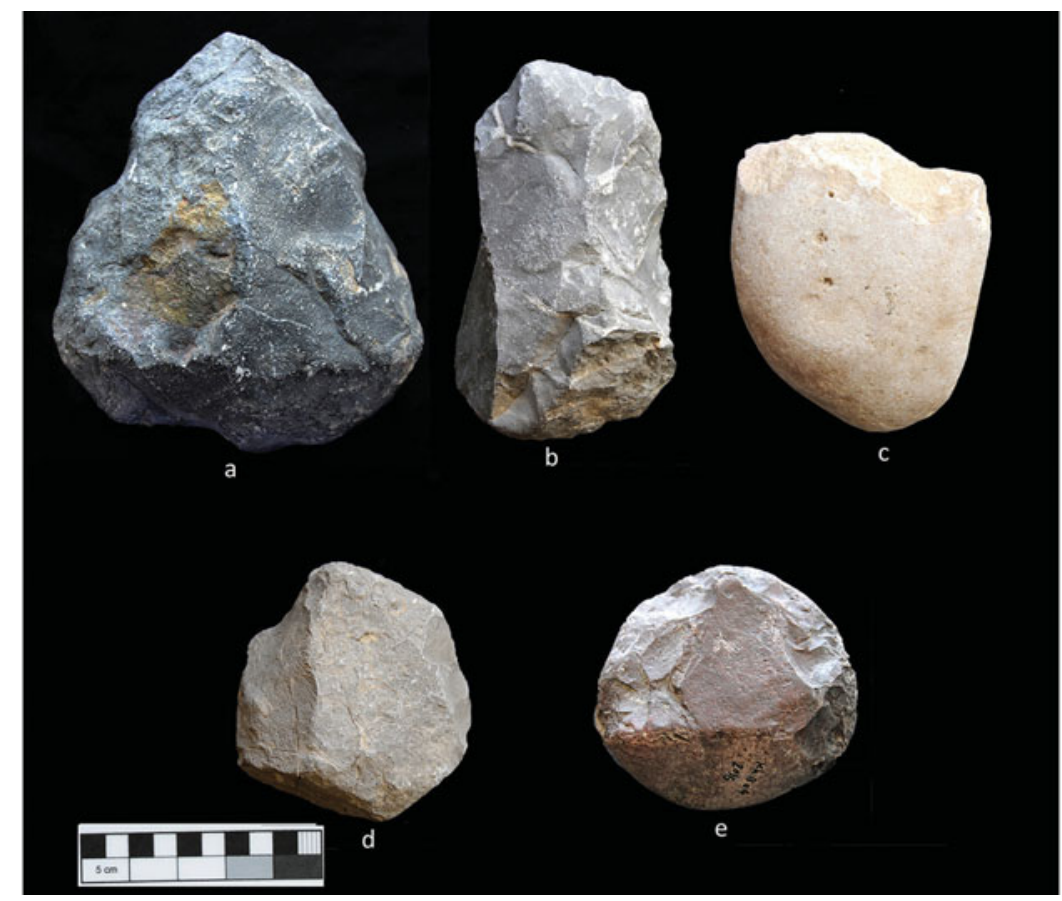

Figure 2. Photograph of Lower Palaeolithic artefacts from Khorbas: $a-b)$ handaxe; c) chopper; d) core; e) hammerstone.

sources such as high-quality local cherts in the vicinity of the site, the artefacts are all of local limestone.

Another Palaeolithic site on Qeshm Island, at Bam-e Qeshm, was previously identified by survey and subsequently excavated by Iranian archaeologists, providing a Middle Palaeolithic date (Dashtizade 2010; Rahmati 2016). The preliminary analysis of the (C) Antiquity Publications Ltd, 2017 

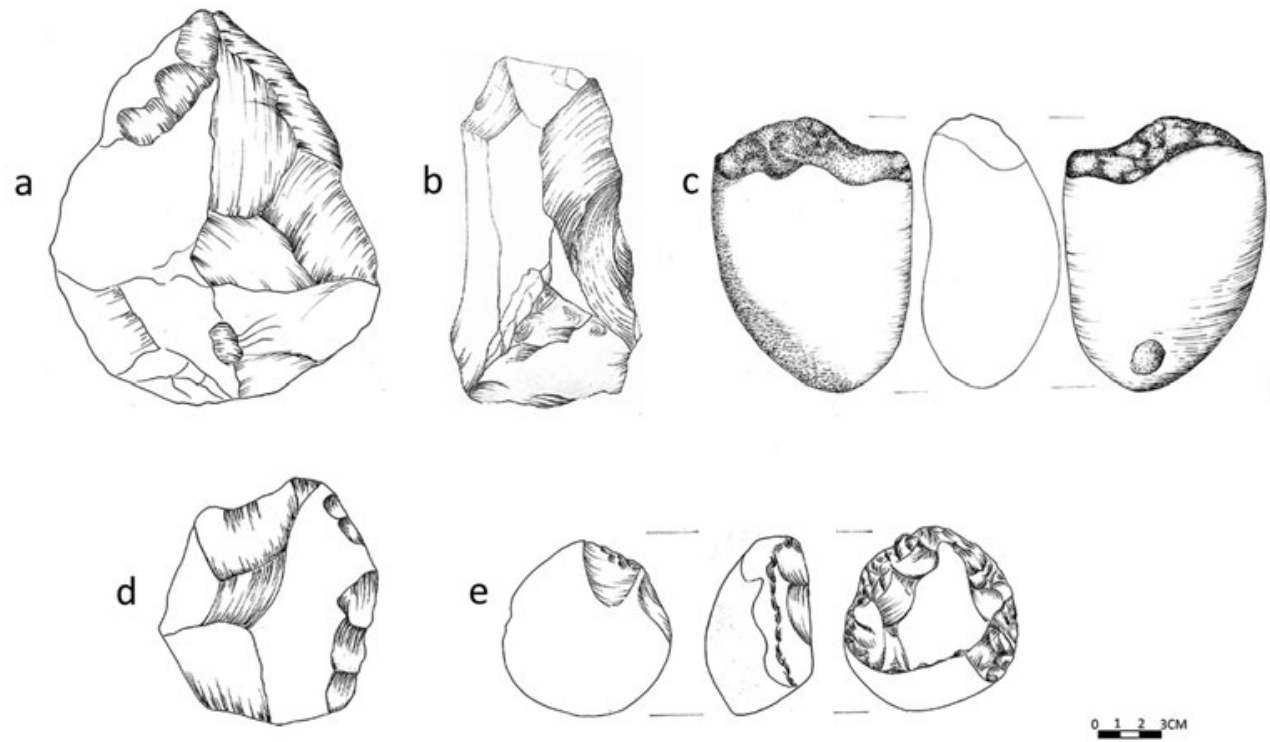

Figure 3. Drawings of Lower Palaeolithic artefacts from Khorbas: $a-b)$ handaxe; c) chopper; d) core; e) hammerstone.

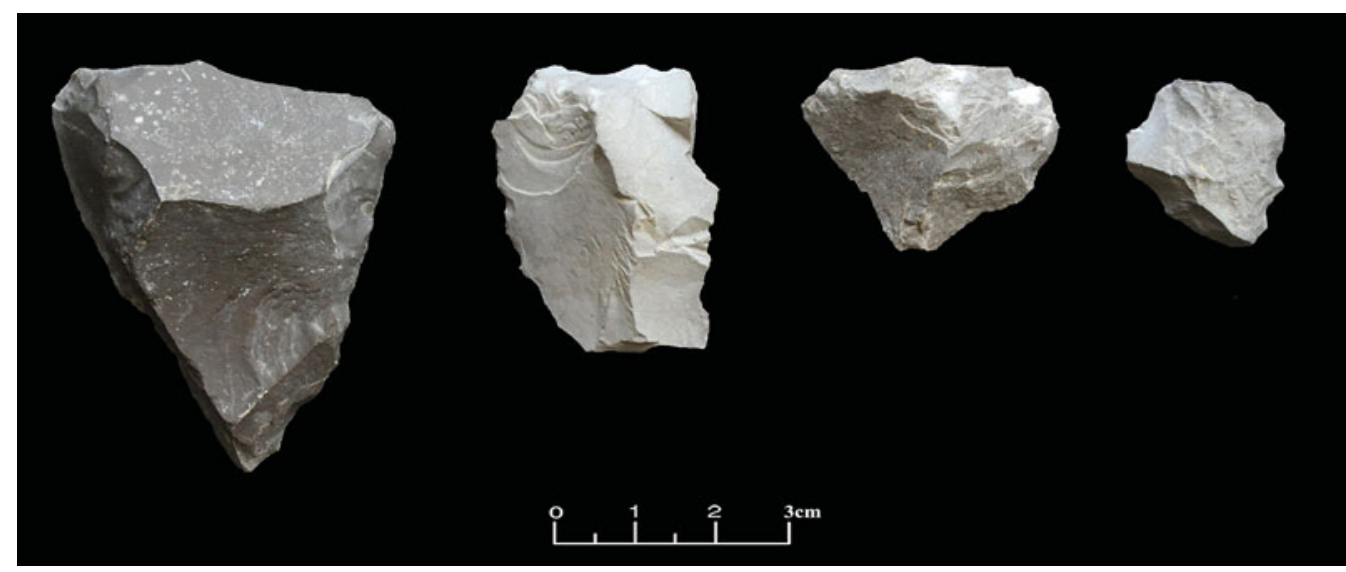

Figure 4. Photograph of Palaeolithic flakes from Khorbas.

artefacts from Khorbas suggests a Lower Palaeolithic date, which would make it the oldest Palaeolithic site yet reported from Qeshm Island.

Reconstructing the specific context and function of the Khorbas site is challenging. It may have been a coastal settlement, but the configuration of the Persian Gulf changed repeatedly during the Pleistocene. Global sea levels during the Last Glacial Maximum (70 000-17000 BP) were up to $120 \mathrm{~m}$ lower than today, and therefore the Persian Gulf was dry during the late Pleistocene. After $17000 \mathrm{BP}$, global sea levels began to rise, reaching approximately modern levels by 7000 BP (Potts 2009). As a result, without closer dating, it

(C) Antiquity Publications Ltd, 2017 

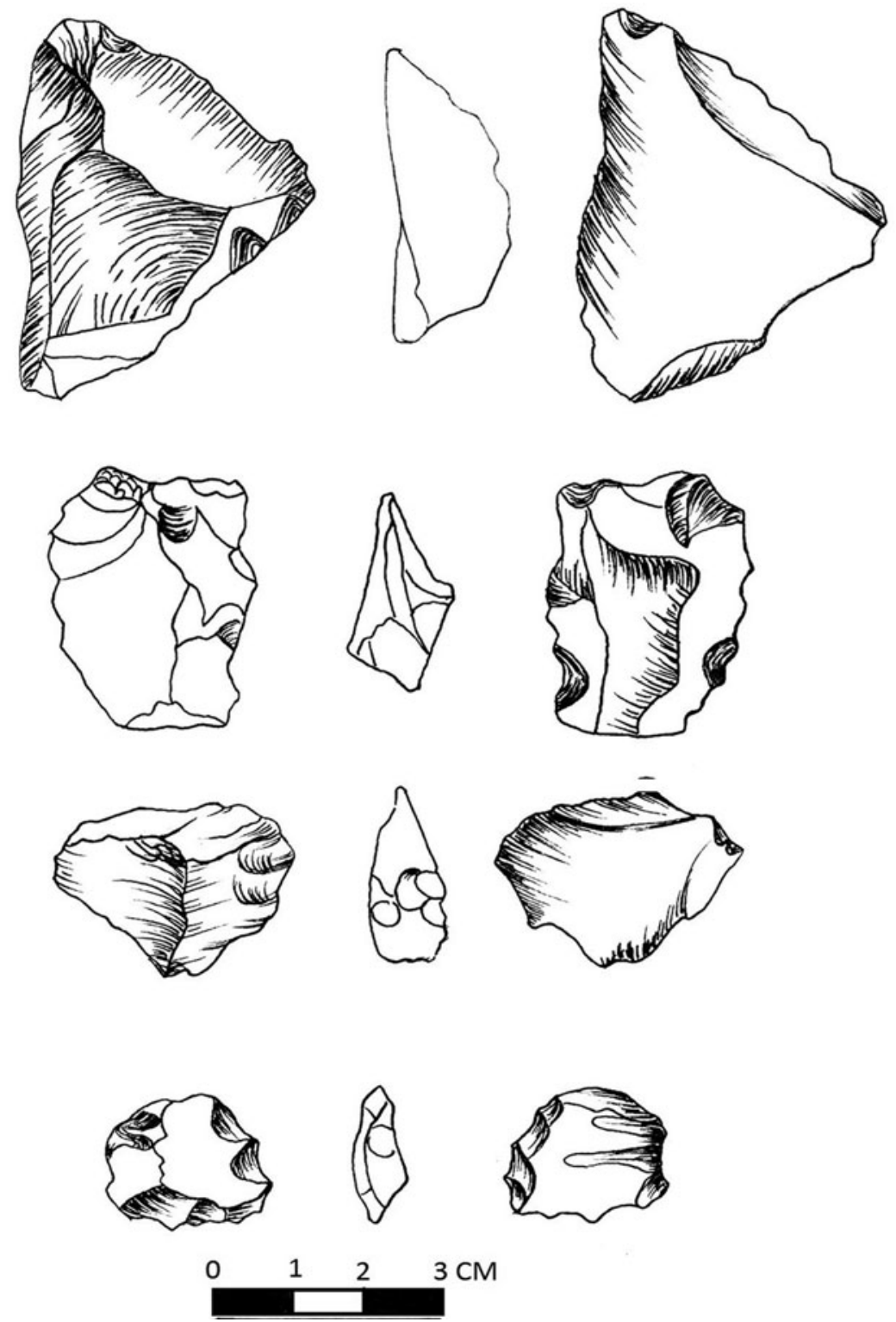

Figure 5. Drawings of Palaeolithic flakes from Khorbas.

is currently impossible to propose any specific context or function for the site. As mentioned above, however, southern coastal Iran has been suggested as one of the routes of early hominin dispersal into western Asia. The discovery of a new Lower Palaeolithic site on Qeshm Island may lend support to this hypothesis. Further work to refine the date of the Khorbas site, and to identify other Lower Palaeolithic sites in this region, should therefore be a priority.

(C) Antiquity Publications Ltd, 2017 


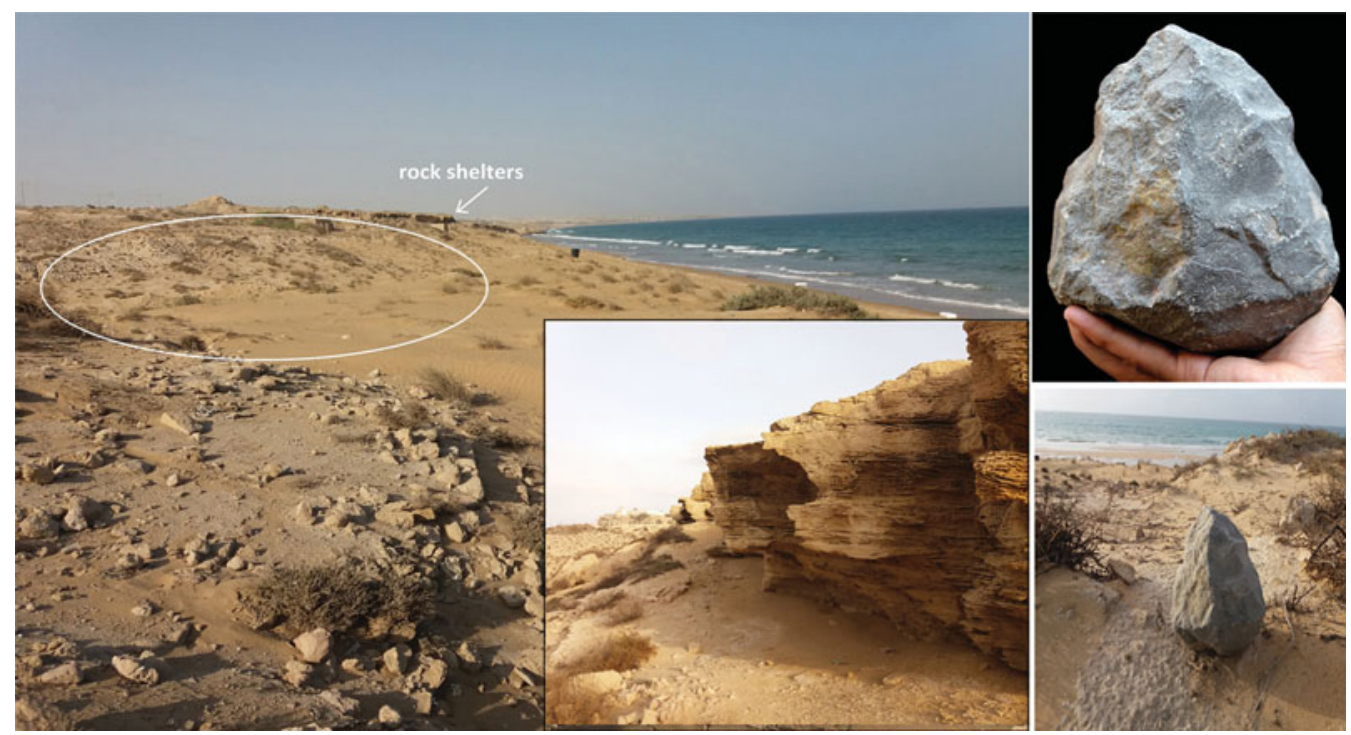

Figure 6. View of the location of the main concentration of material at Khorbas, and a Lower Palaeolithic biface near one of the Khorbas rockshelters.

\section{Acknowledgements}

I would like to thank H. Chobak, Director of the Iranian Center for Archaeological Research, for permission to carry out the Khorbas fieldwork, and also Abdoljavad Kamali, Director of Qeshm Free Area ICHTO, for financial support for the project. I am grateful to Deborah I. Olszewski, Saman Heydari-Guran, Yamandu Hillbert, Anthony Marks and Marcel Otte for their comments on typology and dating of the artefacts. I would also like to thank the project's team members (Iman Saedi and Arman Mahdian), as well as Morteza Zamani Da Daneh, Saeid Bahramain and Mozhgan Seif Panahi for photography and drawings of the lithics.

\section{References}

Bar-Yosef, O. \& A. Belfer-Cohen. 2001. From Africa to Eurasia-early dispersals. Quaternary International 75: 19-28. https://doi.org/10.1016/S1040-6182(00)00074-4

Biglari, F. \& S. Shidrang. 2006. The Lower Palaeolithic occupation of Iran. Near Eastern Archaeology 69(3-4): 106-108.

Dashtizade, A. 2009. Palaeolithic remains from the north coast of the Persian Gulf: preliminary result from the Jam-o-Riz plain, Bushehr province, Iran. Antiquity 83(319): Project Gallery. Available at http://antiquity.ac.uk/projgall/dashtizadeh319/ (accessed 5 May 2017).

- 2010. Preliminary report on the discovery of a late Lower Palaeolithic and Middle Palaeolithic site on the island of Qeshm, Persian Gulf. Iranian Archaeology 1: 17-20.
Khosrowzadeh, A. 2005. The report of the first season of archaeological survey on Qeshm Island. Tehran: Iranian Center for Archaeological Research.

Pоттs, D.T. 2009. The archaeology and early history of the Persian Gulf, in L.G. Potter (ed.) The Persian Gulf in history: 27-56. New York: Palgrave Macmillan.

Potts, D.T. \& C.A. Petrie. 2004. Report on a brief reconnaissance of archaeologically and environmentally significant sites on Qeshm Island. QFZ: 1-30.

Rahmati, M. 2016. Bam-e Qeshm archaeological report. Tehran: Iranian Center for Archaeological Research.

Rose, J.I. 2010. New light on human prehistory on the Arabo-Persian Gulf Oasis. Current Anthropology 51: 849-83. https://doi.org/10.1086/657397 